\title{
Transcatheter paravalvular leak closure and hemolysis - a prospective registry
}

\author{
Grzegorz Smolka ${ }^{1}$, Piotr Pysz ${ }^{1}$, Andrzej Ochała ${ }^{1}$, Michał Kozłowski ${ }^{1}$, Wojciech Zasada ${ }^{2,3}$, \\ Zofia Parma ${ }^{1}$, Michał Tendera' ${ }^{1}$, Wojciech Wojakowski ${ }^{1}$
}

\begin{abstract}
${ }^{1} 3^{\text {rd }}$ Department of Cardiology, Medical University of Silesia, Katowice, Poland ${ }^{2} 2^{\text {nd }}$ Department of Cardiology, University Hospital, Krakow, Poland ${ }^{3}$ Krakow Cardiovascular Research Institute, Krakow, Poland
\end{abstract}

Submitted: 31 January 2016

Accepted: 7 May 2016

Arch Med Sci 2017; 13, 3: 575-584

DOI: 10.5114/aoms.2016.60435

Copyright @ 2016 Termedia \& Banach

\begin{abstract}
Introduction: Paravalvular leak (PVL) related to a surgical prosthetic valve may be associated with clinically significant hemolysis. The influence of transcatheter PVL closure (TPVLC) on hemolysis remains uncertain.

Material and methods: The prospective registry included patients undergoing TPVLC due to PVL-related heart failure and/or hemolysis. Procedural data, laboratory markers of hemolysis and heart failure status were recorded at baseline, discharge and at 1- and 6-month follow-up.

Results: Of 116 patients from all those qualified for TPVLC, 79 fulfilled the inclusion/exclusion criteria. Hemolysis was significantly more frequent in patients with mitral location of PVL and with calcifications in its channel. After TPVLC prompt reduction of lactate dehydrogenase activity (617.0 (342.0-899.0) vs. $397(310.0-480.5) \mathrm{IU} / \mathrm{I}, p<0.05)$ and gradual resolution of anemia (hemoglobin (HGB) 11.7 (10.4-13.8) vs. 13.4 (12.9-13.8) g\%, $p<0.05)$ over 6 months were noted. Effective closure of PVL (>90\% reduction of PVL cross-sectional area) resulted in a more prominent increase of red blood cell count and HGB than in patients with residual regurgitation. The TPVLC-related exacerbation of hemolysis was recorded in 14 patients. Its risk was aggravated by presence of significant hemolysis at baseline or residual flow either by a partially uncovered channel or across the occluder. Reduction of hemolysis after successful TPVLC was sustained in 6-month follow-up. Conclusions: Risk factors for PVL-related hemolysis were the presence of calcifications in the defect and mitral location of PVL. The TPVLC effectively reduced hemolysis if at least $90 \%$ reduction of PVL cross sectional area was achieved. The effect was sustained in 6-month follow-up. Incomplete closure of PVL may increase the magnitude of hemolysis after TPVLC, but it occurred rarely.
\end{abstract}

Key words: paravalvular leak, occluder, percutaneous closure, hemolysis.

\section{Introduction}

Hemolysis and anemia may occur after heart valve replacement surgery as a result of turbulent flow pattern and erythrocyte destruction. They can be caused by imperfect design of old-generation prostheses, but currently the development of paravalvular leak (PVL) is more frequently the reason [1]. The incidence of clinically relevant PVL in patients with a surgical prosthetic valve is estimated at a few percent [2-4]. The $P V L$ is considered significant if it causes heart failure (HF) symptoms

\author{
Corresponding author: \\ Grzegorz Smolka MD, PhD, \\ FESC \\ $3^{\text {rd }}$ Department of Cardiology \\ Medical University of Silesia \\ 45-47 Ziołowa St \\ 40-635 Katowice, Poland \\ Phone: +48 501201622 \\ E-mail: grsm18@wp.pl
}


and/or hemolytic anemia. In such patients surgical correction is associated with high mortality and also with a substantial recurrence rate [5-8]. Therefore transcatheter PVL closure (TPVLC) is a valid alternative. It was first reported by Hourihan et al. in 1992 [9]. Over the subsequent years its safety and feasibility were documented both in children [10] and adults [11-14]. Despite the lack of randomized trials, consistent data from case series and registries resulted in the TPVLC class Ila recommendation being granted by the American Heart Association/American College of Cardiology [15]. This was mainly based on proven effectiveness of TPVLC in reduction of HF symptoms.

The effects of TPVLC on hemolysis and anemia have not been systematically studied in prospective studies despite the clinical significance of this problem. Full exclusion of the PVL by an occluder has the potential to reduce the hemolytic anemia. On the other hand, some case reports have suggested that TPVLC may exacerbate the hemolysis. Our prospective single-center registry systematically evaluated the long-term outcomes of all patients with significant PVL related to surgical valve replacement (SVR) treated with TPVLC. In the current study we investigated the population of patients presenting with HF related to PVL and/ or coexisting hemolytic anemia in order to evaluate the long-term effects of TPVLC on anemia recovery and to identify potential factors leading to postprocedural hemolysis.

\section{Material and methods}

The current report on hemolysis is based on data from a prospective registry including all consecutive patients with PVL related to SVR referred to our institution for TPVLC. The aim of the study was to evaluate the outcomes of selected patients presenting with heart failure and/or significant hemolysis, and the following criteria were used to identify the target population: age $>18$ years, history of surgical aortic or mitral valve replacement (AVR, MVR) complicated by symptomatic (HF and/ or hemolytic anemia) PVL in whom TPVLC was indicated. Exclusion criteria were as follows: anemia related to factors other than hemolysis (bleeding, cancer, chronic inflammation); presence of multiple PVLs with at least one deemed unsuitable for TPVLC (anatomy, size, location); indications for surgical repair (prosthetic valve instability, structural deterioration of prosthetic valve, need for coronary artery bypass grafting, active infective endocarditis) or unexplained elevation of inflammatory markers (WBC, CRP).

Data were collected during the index hospitalization (on admission and at discharge) and on an ambulatory basis after 1 and 6 months. Demographic, clinical and procedural data were prospectively recorded. Laboratory tests included hemoglobin (HGB) concentration, red blood cell count (RBCC) and lactate dehydrogenase (LDH) activity (values above 400 IU/l were considered a cut-off for hemolysis). If multistage TPVLC was necessary, the follow-up was 6 months after the final procedure. The TPVLC-related hemolysis was defined as a rise in LDH activity by at least $100 \mathrm{IU} / \mathrm{I}$ from the initial value in any of the follow-up samples. Periprocedural (within $24 \mathrm{~h}$ ) and in-hospital MACCE (death/MI/stroke) were recorded. Bleeding events were classified according to VARC-2 criteria [16].

Transthoracic echocardiography (TTE) and transesophageal echocardiography with real-time threedimensional imaging (RT 3D TEE) were performed with the Philips iE33 system. The following parameters were measured: cross-sectional area (CSA), minimum and maximum dimensions of the PVL channel with acquisition of the smallest volume containing the PVL channel in a zoom mode with color Doppler (CD) mapping in single-beat acquisition mode. Multi-planar reconstruction enabled positioning of the measurement plane exactly perpendicular to the PVL. For a sample RT-3D TEE image see Figure $1 \mathrm{~A}$.

Accordingly we determined the type, size and a number of plugs needed for the most complete closure of a PVL. Amplatzer Vascular Plug (AVP) II or III devices were used to achieve at least a 150\% oversizing of the occluders' middle modules' CSA in comparison to the PVL's CSA. To avoid potential instability of multiple occluders a maximum of 4 AVPs were implanted into a single PVL. For the Occlutech Paravalvular Leak Device (PLD) [17] the size was directly matched to the minimum and maximum dimensions of the PVL with no oversizing and used as a single device only. Intraprocedurally, RT 3D TEE was used to guide the procedure and to assess the completeness of PVL sealing (Figure $1 \mathrm{~B}$ ), in particular to visualize residual regurgitant flow through the device (Figure $1 \mathrm{C}$ ). The TTE was repeated after 1 and 6 months to assess the stability of the occluders, function of the prosthetic valve and long-term hemodynamic effect of TPVLC. The RT 3D TEE was performed after 6 months to visualize any new regurgitation or residual PVL. During TPVLC the anatomy of PVL channel including the distribution of calcium deposits was also assessed angiographically at least in 2 orthogonal projections with maximum exposure parameters (Figure $1 \mathrm{D}$ ).

For aortic TPVLC a retrograde transfemoral access was uniformly used, while for mitral TPVLC either transseptal or transapical access was used.

The study was approved by the Ethics Committee of the Medical University of Silesia and supported by a STRATEGMED II grant (National 

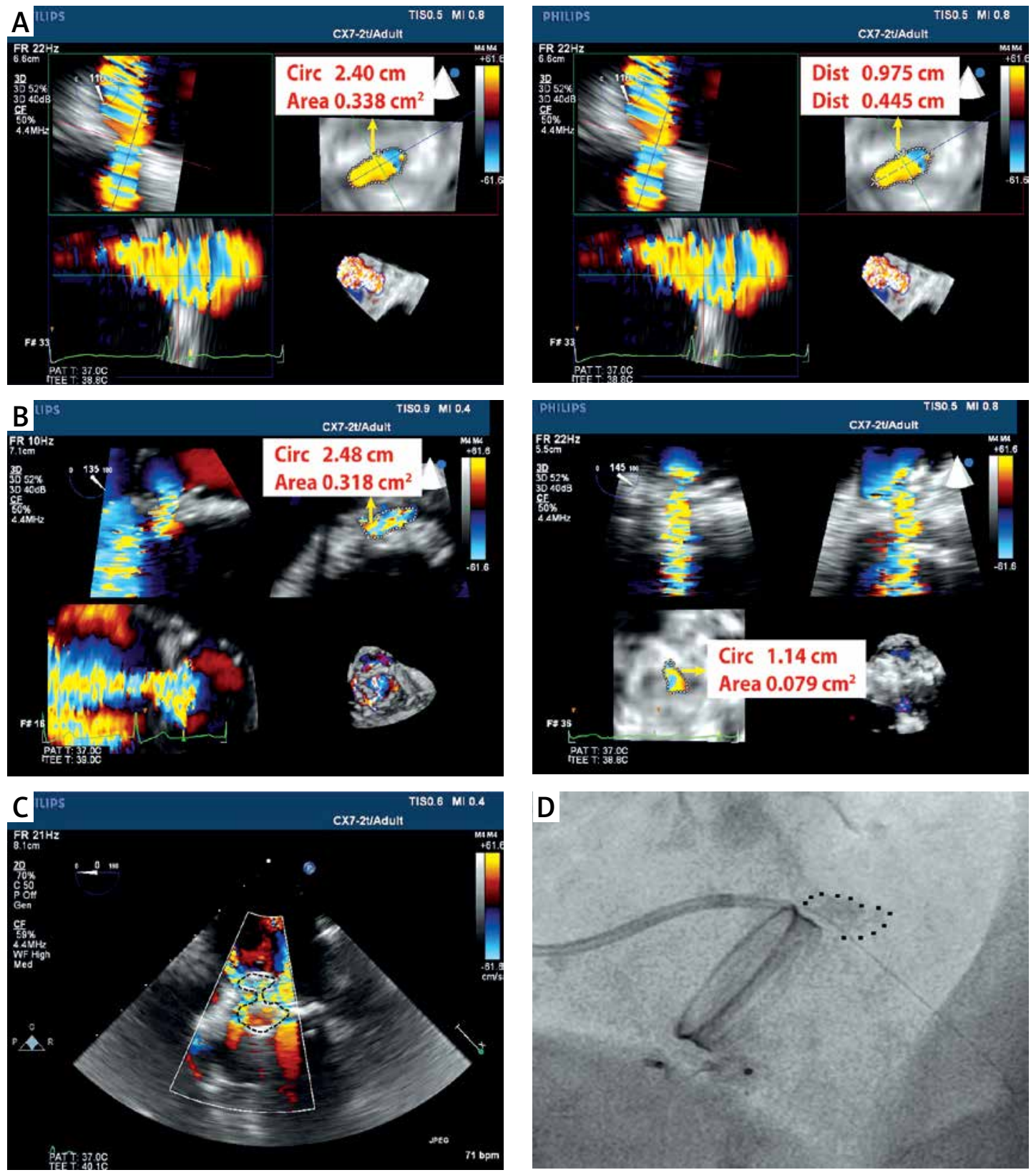

Figure 1. A - Multi-planar reconstruction of RT 3D TEE data set - measurement of CSA (left panel) and minimum and maximum dimensions (right panel) of mitral PVL. B - Assessment of the completeness of PVL sealing - comparison of baseline (left panel) vs. postprocedural (right panel) CSA of PVL - 75\% reduction of aortic PVL CSA. C - Visualization of residual regurgitant flow through the structure of the PLD occluder (dotted black line). D - An example of a calcified PVL channel (dotted black line)

Centre for Research and Development, STRATEGMED2/269488/7/NCBR/2015). All procedures were in accordance with the 1964 Declaration of Helsinki. All patients gave informed consent for TPVLC.

\section{Statistical analysis}

Categorical variables were presented as numbers and percentage. Continuous variables were expressed as mean \pm standard deviation (SD) or median and interquartile range (IQR). Differences between groups were compared using Student's or Welch's t-test depending on the equality of variances for normally distributed variables. The Mann-Whitney $U$ test was used for non-normally distributed continuous variables. Normality was assessed by the Shapiro-Wilk test. Equality of variances was assessed using Levene's test. Categorical variables were compared by Fisher's exact test for $2 \times 2$ tables. For tables with more than two rows or columns Pearson's $\chi^{2}$ test was used. The Pearson correlation coefficient was calculated to measure the linear dependence between two nor- 
Table I. Baseline demographic and clinical data

\begin{tabular}{|c|c|}
\hline Parameter & Result \\
\hline Number of patients & 79 \\
\hline Male, $n(\%)$ & $39(52)$ \\
\hline Age, mean \pm SD [years] & $63.7 \pm 11.6$ \\
\hline \multicolumn{2}{|l|}{ Chronic medications, $n(\%)$ : } \\
\hline VKA & $45(57)$ \\
\hline DAPT & $7(9)$ \\
\hline NOAC & $5(6)$ \\
\hline LVEF, mean \pm SD [\%] & $39 \pm 7.8$ \\
\hline $\begin{array}{l}\text { Severe chronic kidney disease } \\
\left(\text { GFR } 15-29 \mathrm{ml} / \mathrm{min} / 1.73 \mathrm{~m}^{2}\right) / \\
\text { end-stage kidney disease } \\
\left(\text { GFR }<15 \mathrm{ml} / \mathrm{min} / 1.73 \mathrm{~m}^{2}\right), n(\%)\end{array}$ & $5(6) /$ none \\
\hline Diabetes, $n(\%)$ & $23(29)$ \\
\hline $\begin{array}{l}\text { History of coronary } \\
\text { revascularization, } n(\%)\end{array}$ & $29(37)$ \\
\hline EuroSCORE II (logistic) & $11.3(5.6-17.6)$ \\
\hline $\begin{array}{l}\text { Endocarditis before valve } \\
\text { replacement, } n(\%)\end{array}$ & $8(10)$ \\
\hline \multicolumn{2}{|l|}{$\begin{array}{l}\text { Number of previous target valve } \\
\text { replacements: }\end{array}$} \\
\hline 1 & 43 \\
\hline 2 & 29 \\
\hline 3 & 5 \\
\hline $\begin{array}{l}\text { Time from valve replacement } \\
\text { to TPVLC [months] }\end{array}$ & $24(12-43.5)$ \\
\hline $\begin{array}{l}\text { PVL at biological prosthesis, } \\
n(\%)\end{array}$ & $30(38)$ \\
\hline $\begin{array}{l}\text { PVL at mechanical prosthesis, } \\
n(\%)\end{array}$ & $49(62)$ \\
\hline $\begin{array}{l}\text { Coexistence of mitral and aortic } \\
\text { mechanical prosthesis, } n(\%)\end{array}$ & $25(32)$ \\
\hline $\begin{array}{l}\text { Hemodynamically important } \\
\text { PVL, } n(\%)\end{array}$ & $71(90)$ \\
\hline \multicolumn{2}{|l|}{ Hemolysis parameters: } \\
\hline Baseline LDH [IU/I] & $\begin{array}{c}698.0 \pm 499.5 \\
617.0(342.0-899.0)\end{array}$ \\
\hline Hemoglobin $[\mathrm{g} / \mathrm{dl}]$ & $\begin{array}{c}12.1 \pm 2.1 \\
11.7(10.4-13.0)\end{array}$ \\
\hline $\operatorname{RBCC}\left[\mathrm{M} / \mathrm{mm}^{3}\right]$ & $\begin{array}{c}3.9 \pm 0.7 \\
3.9(3.3-4.1)\end{array}$ \\
\hline $\begin{array}{l}\text { Need for transfusion/ } \\
\text { erythropoietin administration }\end{array}$ & $9(11 \%) /$ none \\
\hline $\begin{array}{l}\text { Number of patients with } \\
\mathrm{LDH}>400 \mathrm{IU} / \mathrm{I}\end{array}$ & 50 \\
\hline $\begin{array}{l}\text { Number of patients with } \\
\mathrm{HGB}<11 \mathrm{~g} / \mathrm{dl}\end{array}$ & 42 \\
\hline
\end{tabular}

mally distributed variables. For non-normally distributed variables Spearman's rank correlation coefficient was calculated to measure the monotonic trend. Multivariate models were fitted using backward stepwise regression with the Wald $\chi^{2}$ $p<0.05$ threshold stopping rule. Potential confounders (age and gender) were included in the models a priori.

Two-sided $p$-values $<0.05$ were considered statistically significant in all analyses. All calculations were done with JMP, version 9.0.0, SAS Institute Inc., Cary, NC, 1989-2007.

\section{Results}

One hundred sixteen patients underwent TPVLC in our institution between 2010 Jan and 2015, and 79 of them were enrolled in this hemolysis registry. The inclusion and exclusion criteria were described in the methods section. From 116 patients 37 were excluded for the following reasons: bleeding episodes (mostly patients requiring anticoagulation and dual antiplatelet therapy, $n=$ 19), presence of multiple PVL, with at least one unsuitable for TPVLC $(n=11)$, current anti-neoplastic therapy $(n=4)$, deficiency anemia $(n=3)$.

Preprocedural hemolysis was present in $50 \mathrm{pa}$ tients. It was accompanied by severe anemia requiring transfusion in 9 patients. The majority of patients had a mechanical prosthetic valve.

Forty-three patients were treated due to mitral and 33 due to aortic PVL. The following surgical valves were implanted: aortic (ATS (ATS Medical), $n=11$, SJM Regent (St Jude Medical), $n=8$, Hancock Ultra (Medtronic), $n=7$, St Jude Epic (St Jude Medical), $n=5$, Cardiomedics (Sorin), $n=2$ ) and mitral (ATS (ATS Medical), $n=14$, Carpentier (Edwards Perimount (Edwards), $n=13$, SJM (St Jude), $n=9$, Hancock/Hancock II (Medtronic), $n=5$, Sorin Bicarbon (Sorin), $n=5$ ). The SVR procedures were done with routinely used techniques (AVR with decalcification and supra-annular position and MVR with single sutures and pledgets). Patients were referred from 5 cardiac surgery centers.

Further demographic and initial clinical data are presented in Table I.

\section{Procedural characteristics}

Fifty-four patients underwent a single-stage TPVLC and 25 patients had a two-stage procedure. AVP II or III devices were used in 70 cases and PLD devices in 9 cases. All patients completed the 6-month follow-up. More procedural details are presented in Table II.

In-hospital major adverse cardiovascular and cerebrovascular event (MACCE) (non-disabling stroke presenting as aphasia that fully resolved) occurred in 1 patient. There was 1 case of life- 
threatening intrapleural bleeding after the transapical procedure that warranted transfusion of 3 RBCC units. No other major bleeding occurred. There were 4 cases of minor access site bleeding that resolved with conservative management.

During 6 months there were no late procedural complications (occluder dislocations, recurrence of significant PVL, surgical valve replacement). One patient required two hospitalizations and PRBC transfusion due to persistent hemolytic anemia associated with incomplete closure of the PVL. One patient with incomplete TPVLC on the mitral prosthetic valve required hospitalization at month 4 due to decompensated HF.

\section{Factors influencing the preprocedural hemolysis}

Patients were stratified according to the presence of significant baseline PVL-related hemolysis, and characteristics of both groups are shown in Table III. Patients with significant preprocedural hemolysis more often presented with a calcified PVL channel as assessed by fluoroscopy. Mitral location of the PVL was also more frequent in this group as compared to patients without anemia.

\section{Influence of transcatheter paravalvular leak closure on hemolysis}

The TPVLC led to a significant reduction of the LDH activity already at discharge followed by a further decrease in long-term follow-up between months 1 and 6 (Figure 2). Consistently the RBCC and HGB levels gradually increased. Values of LDH activity, RBCC, and HGB concentration are presented in Table IV.

Only 1 patient, suffering from severe baseline hemolysis, with irregularly shaped and heavily calcified PVL with hemodynamically mild post-procedural residue, required PRBC transfusions after TPVLC.

There were $14(19.7 \%)$ patients who fulfilled criteria of TPVLC-related hemolysis during the follow-up. LDH activities found in these subjects are presented in Figure 3. The HGB concentrations in the TPVLC-related hemolysis group and other patients are comparatively presented in Table $\mathrm{V}$. As shown, TPVLC-related hemolysis was related to a gradual decrease in HGB concentration, but the difference between the groups was statistically insignificant. Except for the patient mentioned above, it did not prove clinically relevant over the 6-month follow-up, either.

To determine whether baseline LDH activity influenced its post-procedural value the correlation between consecutive samples (baseline/discharge/1 month/6 months) was sought individually for each patient. The results are presented in Figure 4. Remarkably, a positive correlation was
Table II. Procedural characteristics

\begin{tabular}{|lc}
\hline Variable & Result \\
\hline Mitral PVLs: & \\
\hline Total number of patients & 46 \\
\hline Single PVL & 35 \\
\hline Multiple PVL (2) & 11 \\
\hline Total number of procedures & $\begin{array}{c}60 \text { (incl. closure } \\
\text { of 2 PVLs in } \\
\text { the same } \\
\text { patient during } \\
\text { the same } \\
\text { procedure) }\end{array}$ \\
\hline Multi-stage procedures & 14 \\
\hline Planned & 10 (multiple \\
& PVLs) \\
\hline After failed 1st attempt & $\begin{array}{c}\text { (switch to } \\
\text { transapical } \\
\text { access) }\end{array}$ \\
\hline
\end{tabular}

Implanted occluders (per PVL):

\begin{tabular}{lc}
\hline $1 \times$ AVP II & 2 \\
\hline $2 \times$ AVP II & 2 \\
\hline $1 \times$ AVP III & 7 \\
\hline $2 \times$ AVP III & 18 \\
\hline $3 \times$ AVP III & 19 \\
\hline $4 \times$ AVP III & 6 \\
\hline $1 \times$ PLD & 6 \\
\hline umber of transseptal procedures & 49 \\
\hline Planned access & 11 \\
\hline After failed transseptal attempt & 4 \\
\hline
\end{tabular}

Aortic PVLs:

Total number of patients: 33

\begin{tabular}{lc|}
\hline Single PVL & 22 \\
\hline Multiple PVL (2) & 9 \\
\hline Multiple PVL (3) & 2 \\
\hline otal number of procedures: & 44 \\
\hline Multi-stage procedures & 11 \\
\hline Planned & 11 \\
\hline After failed 15t attempt & 0 \\
\hline planted occluders (per PVL): & 2 \\
\hline $1 \times$ AVP II & 1 \\
\hline $2 \times$ AVP II & 5 \\
\hline $1 \times$ AVP III & 22 \\
\hline $2 \times$ AVP III & 11 \\
\hline $3 \times$ AVP III & 3 \\
\hline $1 \times$ PLD & \\
\hline
\end{tabular}


Table III. Comparison of patients with and without significant hemolysis

\begin{tabular}{|c|c|c|c|}
\hline \multirow[t]{2}{*}{ Parameter } & \multicolumn{2}{|c|}{ LDH1 } & \multirow[t]{2}{*}{$P$-value } \\
\hline & $\leq 400 \mathrm{IU} / \mathrm{l}$ & $>400 \mathrm{IU} / \mathrm{I}$ & \\
\hline Age [years] & $66.0(59.5-74.5)$ & $63.0(58.0-73.0)$ & 0.1081 \\
\hline LVEF [\%] & $42.24 \pm 8.4$ & $43.9 \pm 7.8$ & 0.3085 \\
\hline $\mathrm{HGB}[\mathrm{g} / \mathrm{dl}]$ & $14.1(13.3-15.2)$ & $10.7(10.1-11.7)$ & $<0.0001$ \\
\hline $\mathrm{RBCC}\left[\mathrm{M} / \mathrm{mm}^{3}\right]$ & $4.5(4.1-5.0)$ & $3.7(3.1-3.9)$ & $<0.0001$ \\
\hline LDH $[I U / I]$ & $268.0(186.8-343.0)$ & $781.0(662.0-1110.0)$ & $<0.0001$ \\
\hline PVL related to biological/mechanical prosthesis, $n$ (\%) & $10(34.5) / 19(65.5)$ & $20(40.0) / 30(60.0)$ & 0.8103 \\
\hline PVL related to mitral/aortic prosthesis, $n(\%)$ & $12(41.4) / 17(58.6)$ & $34(68.0) / 16(32.0)$ & 0.0326 \\
\hline Both prostheses mechanical, $n(\%)$ & $8(27.6)$ & $17(34.0)$ & 0.6222 \\
\hline PVL calcifications & $4(13.8)$ & $32(64.0)$ & $<0.001$ \\
\hline
\end{tabular}

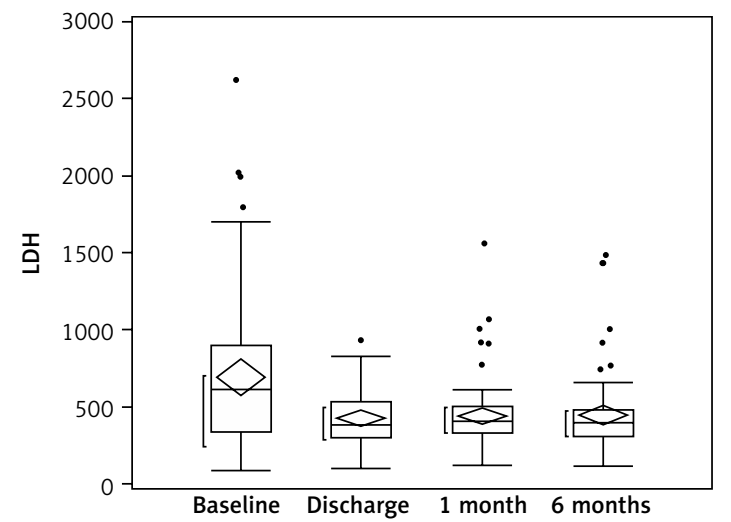

Figure 2. Lactate dehydrogenase activity during 6-month follow-up in all patients

found in each compared pair of samples - greater magnitude of hemolysis prior to TPVLC predicted higher LDH activity in follow-up.

\section{Relation between degree of PVL sealing and hemolysis}

Efficacy of PVL sealing was assessed in 75 patients by comparison of residual CSA after deployment of plugs to its baseline value. Four patients were excluded from this analysis on the grounds of insufficient quality of post-procedural echocardiography images (acoustic shadowing by plugs).

Generally, degree of residual PVL (percentage of uncovered PVL CSA) correlated negatively with in- crease of RBCC $(r=-0.24 ; p=0.04)$ and positively with LDH activity $(r=0.28 ; p=0.03)$ in 1-month follow-up.

Next, patients with complete sealing of the PVL $(n=30)$ were compared to those with any degree of the residual leak. There were higher average values of HGB concentration and RBCC in the first group, but statistical significance was only reached in the case of $\mathrm{LDH}$ activity at discharge: $367.1 \pm 183.6$ vs. $474.7 \pm 185.0 \mathrm{IU} / \mathrm{l}(p=0.0263)$, respectively.

Additionally, an attempt was made to identify a degree of $P V L$ reduction which would ensure a beneficial effect on hemolysis. We found a decrease of PVL CSA by at least $90 \%$ to result in a more prominent increase of RBCC and HGB concentration. Though statistically insignificant, there was also a greater average LDH activity reduction at the same CSA reduction threshold (Table VI).

Finally, we used logistic analysis to identify risk factors for TPVLC-related hemolysis among the following: age, sex, site and type of prosthesis (biological/mechanical), presence of 2 prosthetic valves, left ventricular ejection fraction (LVEF), baseline values of laboratory markers (LDH activity, HGB concentration and RBCC), flow across the occluding device on TEE after deployment, and PVL CSA before and after the procedure. Contrary to baseline presentation, the TPVLC-related hemolysis occurrence rate was not affected by PVL location. The risk of this complication turned out

Table IV. Laboratory markers of hemolytic anemia for all patients

\begin{tabular}{|lcccc|}
\hline Parameter & Baseline (1) & Discharge (2) & 1 month (3) & 6 months (4) \\
\hline HGB $[\mathrm{g} / \mathrm{dl}]$ & $11.7(10.4-13.8)$ & $11.4(10.1-13.0)$ & $12.9(12.0-13.9)^{\star}$ & $13.4(12.9-13.8)^{\star}$ \\
\hline RBCC $\left[\mathrm{M} / \mathrm{mm}^{3}\right]$ & $4.1(3.9-4.5)$ & $3.7(3.3-4.1)$ & $4.2(3.9-4.5)$ & $4.4(4.2-4.7)^{\star}$ \\
\hline LDH $[\mathrm{IU} / \mathrm{ll}]$ & $617.0(342.0-899.0)$ & $388.0(300.0-539.0)^{\star}$ & $412(334.0-507.0)^{*}$ & $397(310.0-480.5)^{\star}$ \\
\hline
\end{tabular}

${ }^{*} p<0.05$ for comparison with baseline values. 
to be related to initially present significant hemolysis $(p=0.0264)$ and identification of residual regurgitant flow across the structure of the occluder(s) by color flow mapping on TEE $(p=0.0007)$. The latter increased the risk by 5 -fold at 1 month (95\% Cl: $1.3-26.4 ; p=0.0331$ ) and 4.6-fold at 6 months (95\% Cl: $1.1-24.7 ; p=0.0374)$. Secondly, each additional CSA square millimeter of residual PVL (across uncovered parts of the channel) corresponded to 9.7-fold increase of post-procedural TPVLC-related hemolysis risk (95\% Cl: 1.5-100.7; $p=0.0151)$.

\section{Discussion}

One of the fundamental studies on mechanisms of PVL-related hemolysis [18] introduced the concept of jet fragmentation on irregular walls of a paravalvular defect. The same phenomenon, probably occurring in the presence of a calcified (and then often irregularly shaped) PVL channel, could explain our findings that patients with significant preprocedural hemolysis more often presented with a calcified PVL channel as assessed by fluoroscopy.

Some previously published papers addressed the possibility of a bidirectional influence of TPVLC on hemolysis, occasionally also hinting at the significance of TPVLC completeness [19-24]. Ruiz et al. reported a reduction in the need for transfusion or erythropoietin administration from an initial $56 \%$ to $5 \%$ at follow-up [25]. In the largest hitherto published series of patients undergoing TPVLC $(n=136$, the majority treated due to PVL-related $\mathrm{HF})$ hemolytic anemia was post-procedurally present in 14 of 129 survivors, with only 1 case of hemolysis exacerbation [11]. The authors suggested enhancing TPVLC efficacy in their last 12 patients by the introduction of the multiplug technique, which was also commonly applied to our patients. In a study by Nijenhuis et al. [26] 17\% of patients after transapical TPVLC still required PRBC transfusions even though some reduction of hemolysis markers was noted. The majority of these patients (53\% for mitral and $86 \%$ for aortic location) were treated with single device implantation, predomi-

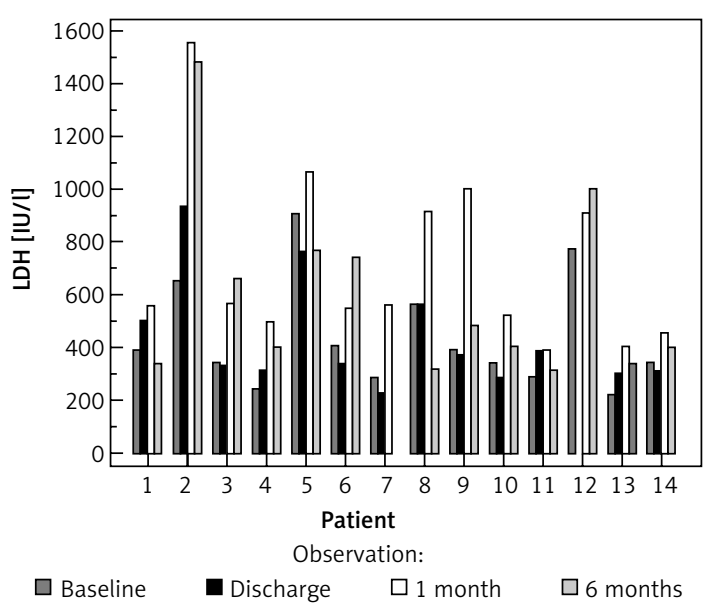

Figure 3. Lactate dehydrogenase activity in patients with TPVLC-related hemolysis

nantly AVP III. As no information on residual flow across the device was published, the explanation of the hemolysis mechanism is difficult. In another publication on TPVLC performed with AVP III devices Cruz-Gonzalez et al. reported a reduction in the need for periodic transfusions from $51.5 \%$ to $9.1 \%$ [27].

In 2015 a meta-analysis of 12 non-randomized studies on TPVLC showed that successful transcatheter reduction of PVL improved NYHA functional class or hemolytic anemia $(n=267$, OR $=$ 9.95; 95\% Cl: 2.10-66.73) [28]. Nevertheless, the evaluation of TPVLC influence on hemolysis alone was impossible because of wide credible intervals for the estimated effect $(n=35, \mathrm{OR}=2.22$, 95\% Cl: 0.06-194).

In our study, a slight decrease in RBCC and HGB concentration was present immediately after TPVLC. Conceivably, this should be attributed to procedural blood loss as the LDH activity lowered promptly and both RBCC and HGB concentration gradually rose during the follow-up in all patients. Exacerbation of hemolysis after TPVLC, which occurred in some patients, resolved during the follow-up, most apparently in the first month. On the other hand, we observed that resolution of baseline hemolytic anemia is not to be expected unless a nearly total occlusion of PVL is achieved intraprocedurally. This is proba-

Table V. HGB concentrations $[\mathrm{g} / \mathrm{dl}]$ in patients with and without TPVLC-related hemolysis

\begin{tabular}{|lccc|}
\hline Time point & $\begin{array}{c}\text { TPVLC-related hemolysis absent } \\
\boldsymbol{N}=\mathbf{6 5}\end{array}$ & $\begin{array}{c}\text { TPVLC-related hemolysis present } \\
\boldsymbol{N}=14\end{array}$ & $\boldsymbol{P}$-value \\
\hline Baseline & $11.9 \pm 2.1$ & $12.1 \pm 2.05$ & 0.1376 \\
& $11.5(10.2-13.8)$ & $11.7(10.4-13.8)$ & $12.0 \pm 1.5$ \\
\hline Discharge & $11.6 \pm 1.7$ & $12.1(11.0-13.4)$ & 0.3372 \\
& $11.2(10.1-13.0)$ & $12.8 \pm 1.9$ & 0.6728 \\
\hline month & $13.0 \pm 1.9$ & $12.7(11.3-14.1)$ & 0.3097 \\
\hline months & $13.0(12.1-13.9)$ & $12.7 \pm 1.5$ & $13.3(11.9-13.7)$ \\
\hline
\end{tabular}




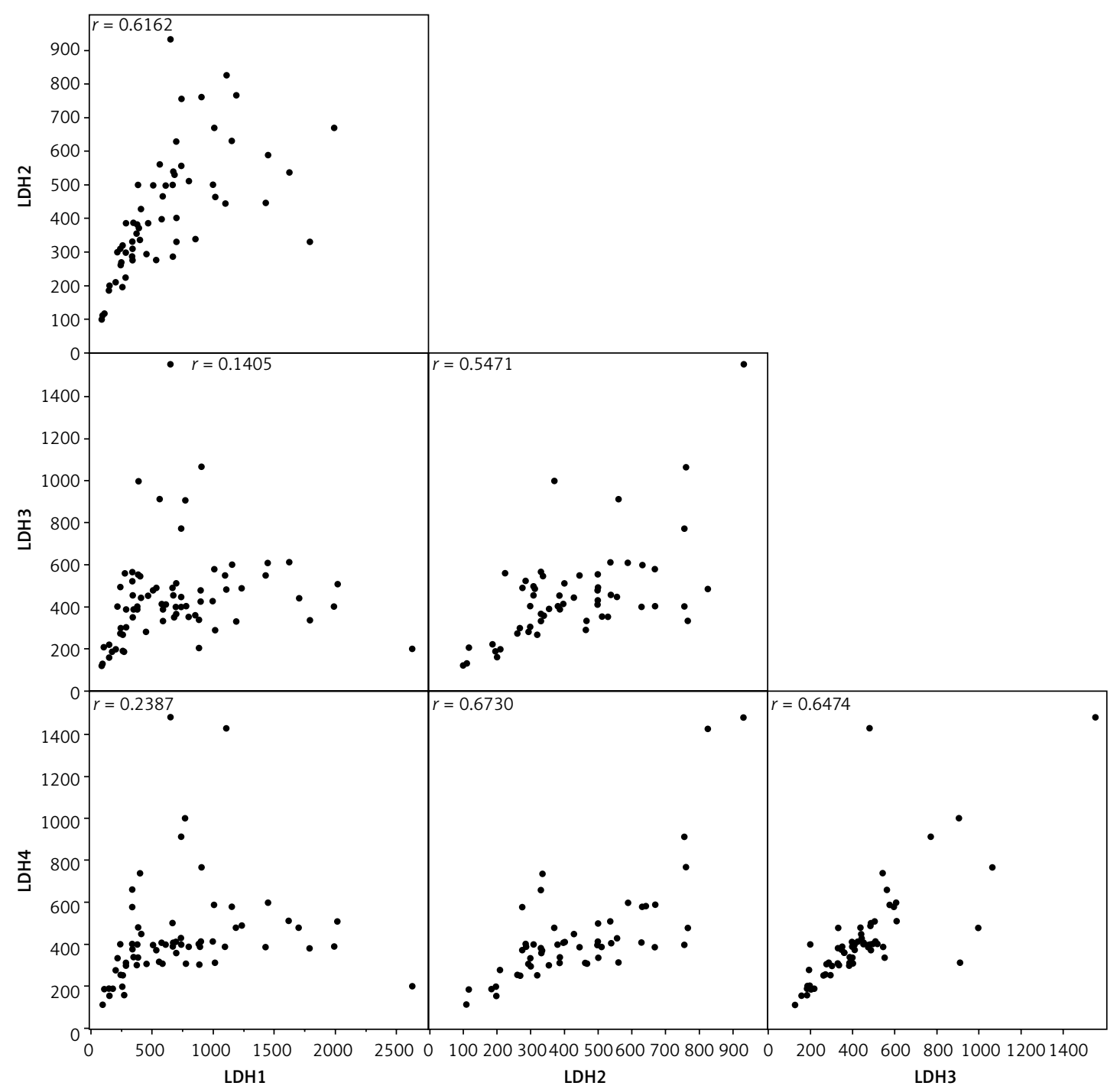

Figure 4. Changes of LDH activity in pairs of samples

Table VI. Changes in HGB concentration, RBC and LDH activity with respect to degree of PVL CSA reduction

\begin{tabular}{|lccc|}
\hline Variable & Reduction of CSA $<90 \%$ & Reduction of CSA $\geq 90 \%$ & $P$-value \\
& $N=16$ & $N=59$ & \\
\hline$\Delta \mathrm{HGB}_{\text {discharge - 1 month }}[\mathrm{g} / \mathrm{dl}]$ & $0.7 \pm 1.1$ & $1.3 \pm 1.0$ & 0.0365 \\
& $0.7(0.2-0.9)$ & $1.2(0.5-2.0)$ & \\
\hline$\Delta \mathrm{HGB}_{\text {baseline - 6 months }}[\mathrm{g} / \mathrm{dl}]$ & $0.0 \pm 1.8$ & $1.6 \pm 1.6$ & 0.0020 \\
\hline$\Delta \mathrm{RBCC}_{\text {discharge - 1 month }}\left[\mathrm{M} / \mathrm{mm}^{3}\right]$ & $0.2 \pm 0.3$ & $0.5 \pm 0.3$ & 0.0007 \\
\hline$\Delta \mathrm{RBCC}_{\text {baseline - 6 months }}\left[\mathrm{M} / \mathrm{mm}^{3}\right]$ & $0.1(-0.1-0.4)$ & $0.5(0.2-0.7)$ & \\
\hline$\Delta \mathrm{LDH}_{\text {discharge - 1 month }}[\mathrm{IU} / \mathrm{l}]$ & $-0.1 \pm 0.7$ & $0.6 \pm 0.5$ & 0.0003 \\
& $0.0(-0.9-0.4)$ & $0.6(0.2-0.9)$ & \\
\hline$\Delta \mathrm{LDH}_{\text {baseline - 6 months }}[\mathrm{IU} / \mathrm{l}]$ & $48.9 \pm 260.5$ & $8.9 \pm 181.4$ & 0.3512 \\
& $38.0(36.8-108.0)$ & $3.0(-88.0-73.0)$ & \\
\hline
\end{tabular}

bly due to high velocity of any residual paravalvular flow, rendering clotting unlikely.

Interestingly, higher LDH activities at baseline were followed by higher values in follow-up in the same patients (even though reduced to some extent by TPVLC). This finding could be related to anatomical features of the PVL channel. We speculate that irregular and calcified PVL channels 
might not only exacerbate hemolysis initially but also continue their effect post-procedurally if left partially uncovered.

We only included patients in whom, based on imaging findings, closure of all PVLs seemed feasible. Consequently, we did not analyze data from patients who were denied TPVLC on grounds of unfavorable anatomy. In many cases, it meant the presence of multiple small PVL channels with sutures in between, which not only hampers TPVLC but also may itself cause significant hemolysis.

Imaging limitations are the next important factor. Echocardiography still lacks a gold standard method of PVL quantification. Quantification of PVL circumferential extent along with a number of traditional regurgitation indicators has been recommended. Still, PVL channel CSA measurement by 3D RT TEE, while enabling both optimal choice of occluding devices and monitoring of the procedure efficacy, seems particularly useful for TPVLC. Identification of sutures crossing the PVL channel, while important for preprocedural planning, may still be challenging with the currently achievable spatial resolution. Assessment of presence and extent of calcifications occupying areas considered as landing zones for occluders is another issue exposed to subjectivity both on echocardiography and fluoroscopy.

Another limitation is the study sample size. In the logistic analysis, PVL CSA was found to have an influence on post-procedural TPVLC-related hemolysis. Nevertheless, the wide confidence interval precludes a firm conclusion. Similarly, only non-significant differences could be identified when comparing effects of total vs. partial PVL sealing.

In conclusion, the risk of significant hemolysis associated with PVL is higher in patients with calcifications visible on fluoroscopy and mitral PVL location. Transcatheter PVL closure significantly reduces hemolysis and leads to an increase of HGB concentration and RBCC in a 6-month follow-up. These effects are dependent on the degree of achieved PVL sealing, and incomplete closure may increase the magnitude of hemolysis after TPVLC. Optimally, the technique used during implantation of the occluders should allow one to avoid any residual leakage, both beside and across the devices' structure. A small percentage of patients experience exacerbation of hemolysis after TPVLC, which usually remains clinically irrelevant. The influence of TPVLC on hemolysis is noticeable shortly after the procedure and persistent in midterm follow-up.

\section{Conflict of interest}

The authors declare no conflict of interest.

\section{References}

1. Horstkotte D, Korfer R, Seipel L, Bircks W, Loogen F. Late complications in patients with Bjork-Shiley and St. Jude Medical heart valve replacement. Circulation 1983; 68: II175-84.

2. O'Rourke DJ, Palac RT, Malenka DJ, Marrin CA, Arbuckle BE, Plehn JF. Outcome of mild periprosthetic regurgitation detected by intraoperative transesophageal echocardiography. J Am Coll Cardiol 2001; 38: 163-6.

3. Rallidis LS, Moyssakis IE, Ikonomidis I, Nihoyannopoulos P. Natural history of early aortic paraprosthetic regurgitation: a five-year follow-up. Am Heart J 1999; 138: 351-7.

4. Davila-Roman VG, Waggoner AD, Kennard ED, et al. Prevalence and severity of paravalvular regurgitation in the Artificial Valve Endocarditis Reduction Trial (AVERT) echocardiography study. J Am Coll Cardiol 2004; 44: 1467-72.

5. de Almeida Brandao CM, Pomerantzeff PM, Souza LR, et al. Multivariate analysis of risk factors for hospital mortality in valvular reoperations for prosthetic valve dysfunction. Eur J Cardiothorac Surg 2002; 22: 922-6.

6. Potter DD, Sundt TM $3^{\text {rd }}$, Zehr KJ, et al. Risk of repeat mitral valve replacement for failed mitral valve prostheses. Ann Thorac Surg 2004; 78: 67-72; discussion 67-72.

7. Akins CW, Bitondo JM, Hilgenberg AD, Vlahakes GJ, Madsen JC, MacGillivray TE. Early and late results of the surgical correction of cardiac prosthetic paravalvular leaks. J Heart Valve Dis 2005; 14: 792-9; discussion 799-800.

8. Noble S, Jolicoeur EM, Basmadjian A, et al. Percutaneous paravalvular leak reduction: procedural and long-term clinical outcomes. Can J Cardiol 2013; 29: 1422-8.

9. Hourihan M, Perry SB, Mandell VS, et al. Transcatheter umbrella closure of valvular and paravalvular leaks. J Am Coll Cardiol 1992; 20: 1371-7.

10. Fiszer R, Smolka G, Szkutnik M, Bialkowski J. Transcatheter aortic paravalvular leak closure using 3 Amplatzer Vascular Plug III devices in a child. Postep Kardiol Inter 2015; 11: 156-7.

11. Sorajja P, Cabalka AK, Hagler DJ, Rihal CS. Long-term follow-up of percutaneous repair of paravalvular prosthetic regurgitation. J Am Coll Cardiol 2011; 58: 2218-24.

12. Smolka G, Pysz P, Wojakowski W, et al. Clinical manifestations of heart failure abate with transcatheter aortic paravalvular leak closure using Amplatzer vascular plug II and III devices. J Invasive Cardiol 2013; 25: 226-31.

13. Smolka G, Pysz P, Jasinski M, et al. Transapical closure of mitral paravalvular leaks with use of Amplatzer vascular plug III. J Invasive Cardiol 2013; 25: 497-501.

14. Smolka G, Pysz P, Jasinski M, et al. Multiplug paravalvular leak closure using Amplatzer Vascular Plugs III: a prospective registry. Catheter Cardiovasc Interv 2016; 87: 478-87.

15. Nishimura RA, Otto CM, Bonow RO, et al. 2014 AHA/ ACC guideline for the management of patients with valvular heart disease: executive summary: a report of the American College of Cardiology/American Heart Association Task Force on Practice Guidelines. J Am Coll Cardiol 2014; 63: 2438-88.

16. Kappetein AP, Head SJ, Genereux P, et al. Updated standardized endpoint definitions for transcatheter aortic valve implantation: the Valve Academic Research Consortium-2 consensus document. J Thorac Cardiovasc Surg 2013; 145: 6-23.

17. Smolka GP, Kozłowski P, Jasiński M, et al. Transcatheter closure of paravalvular leaks using a paravalvular leak device - a prospective Polish registry. Adv Interv Cardiol 2016; 12: 128-34. 
18. Garcia MJ, Vandervoort P, Stewart WJ, et al. Mechanisms of hemolysis with mitral prosthetic regurgitation. Study using transesophageal echocardiography and fluid dynamic simulation. J Am Coll Cardiol 1996; 27: 399-406.

19. Moore JD, Lashus AG, Prieto LR, Drummond-Webb J, Latson LA. Transcatheter coil occlusion of perivalvular mitral leaks associated with severe hemolysis. Catheter Cardiovasc Interv 2000; 49: 64-7.

20. Kuehl M, Schreieck J, Burgstahler C. Percutaneous closure of a periprosthetic leakage after mitral valve reoperation due to recurrent endocarditis. Catheter Cardiovasc Interv 2009; 73: 838-41.

21. Labban B, Radhakrishnan J. The case/Renal failure after percutaneous closure of a perivalvular leak. Kidney Int 2008; 74: 539-40

22. Hein R, Wunderlich N, Robertson G, Wilson N, Sievert H. Catheter closure of paravalvular leak. EuroIntervention 2006; 2: 318-25.

23. Pate GE, Al Zubaidi A, Chandavimol M, Thompson CR, Munt BI, Webb JG. Percutaneous closure of prosthetic paravalvular leaks: case series and review. Catheter Cardiovasc Interv 2006; 68: 528-33

24. Shapira Y, Hirsch R, Kornowski R, et al. Percutaneous closure of perivalvular leaks with Amplatzer occluders: feasibility, safety, and shortterm results. J Heart Valve Dis 2007; 16: 305-13.

25. Ruiz CE, Jelnin V, Kronzon I, et al. Clinical outcomes in patients undergoing percutaneous closure of periprosthetic paravalvular leaks. J Am Coll Cardiol 2011; 58: 2210-7.

26. Nijenhuis VJ, Swaans MJ, Post MC, Heijmen RH, de Kroon TL, Ten Berg JM. Open transapical approach to transcatheter paravalvular leakage closure: a preliminary experience. Circ Cardiovasc Interv 2014; 7: 611-20.

27. Cruz-Gonzalez I, Rama-Merchan JC, Arribas-Jimenez A, et al. Paravalvular leak closure with the Amplatzer Vascular Plug III device: immediate and short-term results. Rev Esp Cardiol (Engl Ed) 2014; 67: 608-14.

28. Millan X, Skaf S, Joseph L, et al. Transcatheter reduction of paravalvular leaks: a systematic review and metaanalysis. Can J Cardiol 2015; 31: 260-9. 